\title{
Interferon Induced Thyrotoxicosis
}

V Salazar, S Whomersley, K E Imtiaz

Lancashire Teaching Hospitals NHS Foundation Trust, Chorley, U.K.

\section{Case Report}

A 44 year old gentleman with history of intravenous drug abuse, was referred for new onset hyperthyroidism. He was diagnosed with Hepatitis $\mathrm{C}$ a year prior to presentation. Treatment included Pegylated-interferon (IFN- a) 100 mcg weekly and Ribavirin $1 \mathrm{~g}$ daily. He had early viral response at week 4 of treatment with viral load of $<30 \mathrm{iu} / \mathrm{ml}$ from 24089iu/ml.

At week 8, patient complained of lethargy. He was tachycardic, but had no goitre or thyroid eye disease. Thyroid function tests(TFTs) revealed a suppressed TSH $<0.02 \mathrm{mU} / \mathrm{l}$ (NR 0.35-5.0), FT4 47.4pmol/L, (NR 11-23), FT3 $12.6 \mathrm{pmol} / \mathrm{L}(\mathrm{NR}$ 3.9-6.8). He was started on Carbimazole $20 \mathrm{mg}$ OD. Anti TPO were positive at 1606.

TSH receptor antibodies were negative and Isotope thyroid scan showed homogenous uptake. His Interferon treatment was stopped at week 18 and Ribavirin was continued. Successful clearance of virus was achieved 6 months post treatment. His thyroid function tests normalized after starting Carbimazole. Then he became hypothyroid, hence Carbimazole was stopped and subsequently, Thyroxine was commenced. Unfortunately, he was lost to follow up.

An overall mean prevalence of incident thyroid dysfunction of $6.2 \%$ on IFN- a treatment has been reported; hypothyroidism occurring more frequently (3.9\%) than hyperthyroidism (2.3\%). Thyroid dysfunction was subclinical, and spontaneous resolution occurred in almost $60 \%$ of patients with or without withdrawal of interferon.

Risk factors for developing thyroid dysfunction were female sex and pre-existing autoimmune thyroiditis. ${ }^{1}$ IFN-a can lead to induction of thyroid autoantibodies. In one study, ten patients developed thyrotoxicosis; six of them had clinical manifestations consistent with Graves' disease, and three had transient thyrotoxicosis, with progression to hypothyroidism after resolution of thyrotoxicosis. ${ }^{2}$

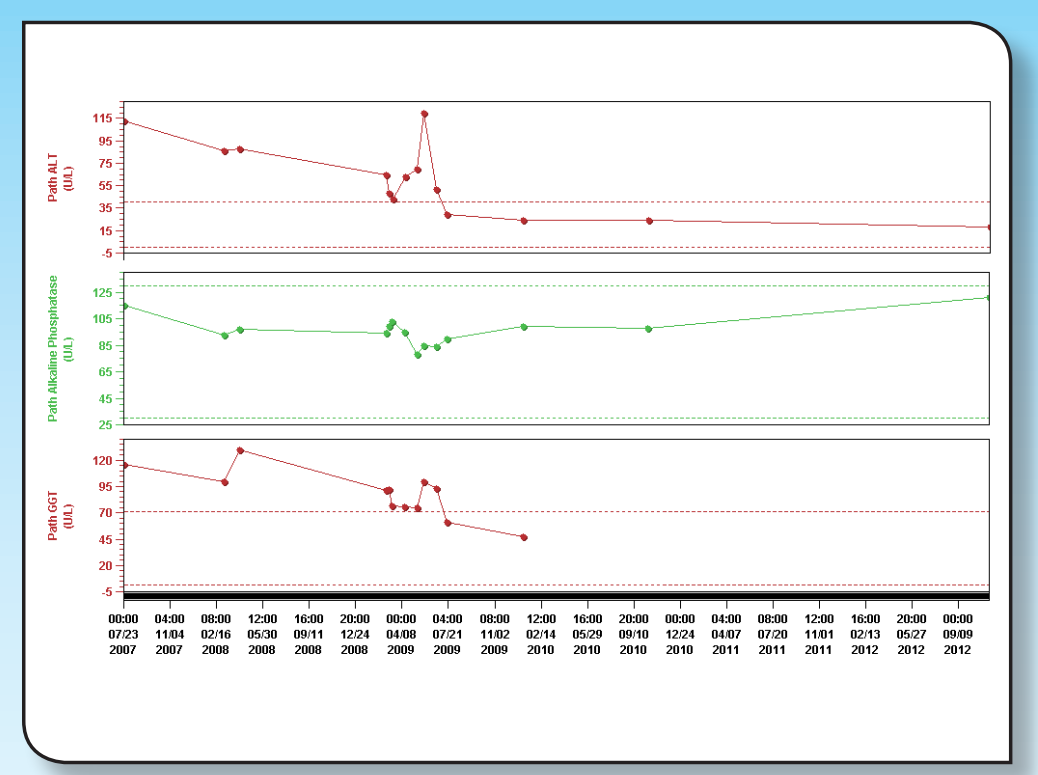

Figure 1. Thyroid function tests over time

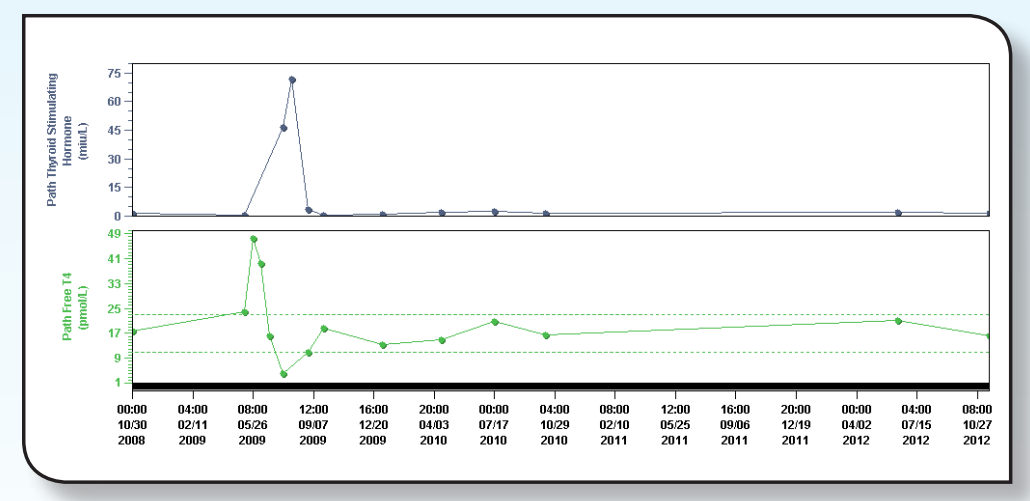

Figure 2. Trend of Liver function tests

\section{Conclusions}

Thyroid dysfunction, especially thyrotoxicosis, is not infrequently observed in patients receiving interferon therapy for chronic active hepatitis. ${ }^{3}$ It is recommended to measure TFTs before starting IFN, during and after it has been discontinued.

\section{References}

1. Monzani F, Caraccio N, Dardano A, Ferrannini E. Thyroid autoimmunity and dysfunction associated with Type 1 Interferon therapy. Clinical and Experimenta Medicine, 04 2004, 3/4 (199-210)

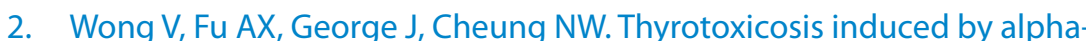
interferon therapy in chronic viral hepatitis. Clinical Endocrinology, 062006 $56 / 6(703-08)$

3. Roti E, Minelli R, Giuberti T et al. Multiple changes in thyroid function in patients with chronic active VCH Hepatitis treated with recombinant interferon-alpha. American Journal of Medicine 11 1996, 101/5 (482-7)

Lancashire Teaching Hospitals

NHS Foundation Trust 